\title{
Adaptive PID Control of UAV Altitude Dynamics Based on Parameter Optimization with Fuzzy Inference
}

\author{
Amr Sarhan and Shiyin Qin
}

\begin{abstract}
This paper developed an adaptive PID flight controller based on parameter optimization with fuzzy inference for controlling the altitude dynamics of the Aerosonde UAV. The online fuzzy inference is used as a self-adaptive mechanism for tuning the PID parameters. The proposed adaptive PID flight controller is compared with two other controllers. The first controller is the genetically-tuned PID controller, and the other is the fuzzy logic controller. The simulation results show the good performance characteristics and good robust stability for the proposed adaptive PID controller.
\end{abstract}

Index Terms-PID control, fuzzy control, adaptive PID control, UAV.

\section{INTRODUCTION}

UAVs play important roles in critical missions. This is because of its low cost and also to protect the human crew in such dangerous missions. An autopilot is used for flight control to track a reference path. The autonomous flight control system has to promise the accuracy of the tracking path and the robustness to environmental disturbances in addition to the uncertainty in UAV model. Small UAVs are sensitive to environmental disturbances especially the wind since its magnitude may be similar to the UAVs speed [1].

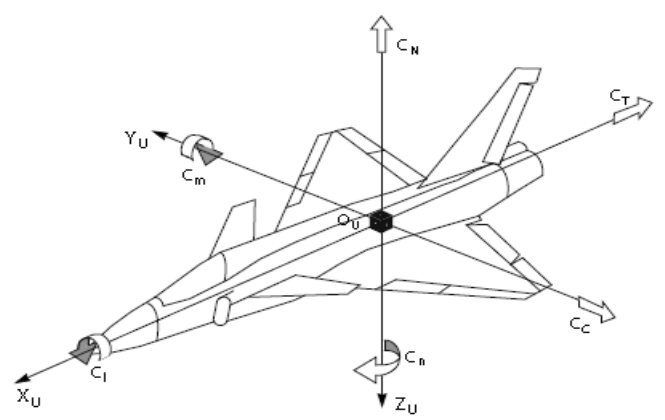

Fig. 1. Aerodynamic force and moment in the body-axis reference frame.

UAV motion in free flight is highly complicated [2] and contains three translation motions and three rotational motions. Two assumptions are assumed to reduce the complexity [3]: the UAV is assumed as rigid-body. In addition, the mass distribution of the UAV is symmetric relative to $\mathrm{X}_{U} \mathrm{O}_{U} \mathrm{Z}_{U}$ plane as in Fig. 1, which implies that, the products $I_{y z}$ and $I_{x y}$ of inertia are equal to zero.

Manuscript received May 4, 2016; revised July 13, 2016. This work partly supported by National Natural Science Foundation of China under Grant 61273350 and Grant U1435220.

Amr Sarhan and Shiyin Qin are with School of Automation Science and Electrical Engineering in Beihang University (Beijing University of Aeronautics and Astronautics) Beijing, China (e-mail: amrsarhan_39@hotmail.com, qsy@buaa.edu.cn).
The UAV performance depends on the flight control system design, which is the heart system of UAV [4]. The traditional flight control system approach is PID algorithm due to its simplicity, easy for implementation in hardware and software, and does not require maintenance [5]. However, the resulting flight controller usually has lower adaptability and does not produce a good performance when tested in more realistic UAV environment [6], [7]. The traditional approach for enhancing the PID performance is to use PID with gain scheduling [8]. However, the switching between different controllers sometimes is not always smooth and it is urgent to design a single flight controller to run for a certain flight envelope [9], [10]. Different control techniques have been developed and verified successfully for UAVs flight control systems such as adaptive control, robust control, predictive control, optimal control, and intelligent control [11], [12].

Notwithstanding, the tuning of PID gains is still a promising investigation field and various techniques for tuning PID gains were developed [13]. The most well-known technique in this field is Ziegler-Nichols. In spite of its simplicity and easiness in tuning the PID gains, its performance is deficient in nonlinear systems [14]. Optimal control is also utilized to tune the PID gains. It is necessary to get an exact mathematical model, so it is difficult in practical implementation [15]. Another tuning technique based on genetic algorithms and differential evolution has been developed in [16]. A self-tuning technique, based on control performance evolution, was presented in [17] to improve transient and steady-state performance. A combination between traditional PID controller and the neural network was developed in [18] to provide strong adaptive and self-learning capability which enhances the traditional PID performance. The particle swarm optimization (PSO) technique was utilized in [19] to design self-tuning PID control.

In this paper, an adaptive PID control of UAV altitude dynamics based on parameter optimization with fuzzy inference is developed. The proposed adaptive PID control is a combination of traditional PID and fuzzy logic control schemes. Two other controllers are designed to be compared with the proposed adaptive PID controller. The first controller is genetically-tuned PID and the second is the fuzzy logic controller. The autopilot performances have been studied with respect to each controller. A comparative study using simulation model of the Aerosonde UAV is held to decide which controller is the best in terms of performance analysis and robustness to external disturbances and model parametric uncertainty. 


\section{NONLINEAR DYNAMIC MODEL OF UAV}

In this section, a brief description of the UAV modeling is provided. UAV modeling is a basis of a simulation environment for development and evaluation of the performance of proposed flight control system. It is more useful to express the UAV motion in the body-axis frame compared to wind-axis frame.

\section{A. Dynamic Model of UAV}

Submit your manuscript electronically for review.

The dynamics of the UAV in motion can be given by Newton's 2nd law which is suitable in the inertial frame. A complete 6-DOF non-linear Aerosonde UAV dynamic model (with body fixed frame) [20] is demonstrated in the forthcoming discussion. The Aerosonde UAV is a system with six degrees of freedom [21], its nonlinear model is described by 12 dynamic variables: body frame velocities $(\mathrm{u}, \mathrm{v}, \mathrm{w})$, Euler angles $(\varphi, \theta, \psi)$, angular velocities $(\mathrm{p}, \mathrm{q}, \mathrm{r})$, and inertial positions $\left(\mathrm{p}_{\mathrm{N}}, \mathrm{p}_{\mathrm{E}}, \mathrm{h}\right)$, on the other hand, the model depends on external forces $\left(f_{x}, f_{y}, f_{z}\right)$ and moments $(l, m, n)$. The dynamic model is summarized in (1)-(4).

Force equations:

$$
\left\{\begin{array}{l}
\dot{u}=r v-q w+\frac{f_{x}}{m} \\
\dot{v}=p w-r u+\frac{f_{y}}{m} \\
\dot{w}=q u-p v+\frac{f_{z}}{m}
\end{array}\right.
$$

Kinematic equations:

$$
\left\{\begin{array}{c}
\dot{\varphi}=p+q \sin \varphi \tan \theta+r \cos \varphi \tan \theta \\
\dot{\theta}=q \cos \varphi-r \sin \varphi \\
\dot{\psi}=\frac{q \sin \varphi+r \cos \varphi}{\cos \theta}
\end{array}\right.
$$

Moment equations:

$$
\left\{\begin{array}{c}
\dot{p}=c_{1} q r+c_{2} p q+c_{3} l+c_{4} n \\
\dot{q}=c_{5} p r-c_{6}\left(p^{2}-r^{2}\right)+c_{7} m \\
\dot{r}=c_{8} p q-c_{2} q r+c_{4} l+c_{9} n
\end{array}\right.
$$

Navigation equations:

$$
\left\{\begin{array}{c}
\dot{p}_{N}=u \cos \theta \cos \psi+v(\sin \varphi \sin \theta \cos \psi-\cos \varphi \sin \psi) \\
\quad+w(\sin \varphi \sin \psi+\cos \varphi \sin \theta \cos \psi) \\
\dot{p}_{E}=u \cos \theta \sin \psi+v(\cos \varphi \cos \psi+\sin \varphi \sin \theta \sin \psi) \\
\quad+w(\cos \varphi \sin \theta \sin \psi-\sin \varphi \cos \psi) \\
\dot{h}=u \sin \theta-v \sin \varphi \cos \theta-w \cos \varphi \cos \theta
\end{array}\right.
$$

where $c_{1}, \ldots, c_{9}$ are functions of moments of inertia $\left(J_{x}, J_{y}, J_{z}\right)$. The forces $\left(f_{x}, f_{y}, f_{z}\right)$ and moments $(l, m, n)$ that acts on the UAV are mainly due to three sources: gravity, aerodynamics, and propulsion. These variables depend on UAV mass $(\mathrm{m})$, gravity $(g)$, Euler angles, density of air $(\rho)$, airspeed $\left(V_{\mathrm{a}}=\sqrt{\mathrm{u}^{2}+\mathrm{v}^{2}+\mathrm{w}^{2}}\right)$, surface area of the wing $(\mathrm{S})$, angular velocities, angle of attack $\left(\alpha=\tan ^{-1}\left(\frac{w}{u}\right)\right)$, side slip angle $\left(\beta=\sin ^{-1}\left(\frac{v}{v_{a}}\right)\right)$, control surface configuration (ailerons $\delta_{\mathrm{a}}$, elevator $\delta_{\mathrm{e}}$, rudder $\delta_{\mathrm{r}}$ ), engine acceleration $\left(\delta_{t}\right)$, area, aerodynamic coefficient and torque of the propeller, the efficiency of the engine, and the aerodynamic coefficients (see [22] for details).

For guidance purpose, the three main variables to be controlled are a longitudinal speed $u(t)$, altitude $h(t)$, and heading angle $\psi(\mathrm{t})$. The two first variables handle the longitudinal movements of the UAV and the last one the lateral movements.

\section{B. Uncertainty Analysis in UAV Model}

Uncertainty in UAV model comes from two sources [10], [23]: stochastic nature of the environment as unpredictable external disturbances and internal UAV model error due to incomplete knowledge of the model. External disturbances are always out of control, such as the high-frequency noise of sensors and gust disturbance. Internal model error of UAV contains measuring error of moment of inertia: $I_{x}, I_{y}, I_{z}, I_{x z}$, and approximation error of aerodynamic force and moment.

The difficulty of controlling uncertain systems is to design a fixed controller which assures the design requirements in the presence of significant uncertainties which mentioned to as the robust control problem [24]. Adaptive control technique, unlike a fixed gain controller, is able to achieve good performance in the presence of significant parametric uncertainties, and even without the full knowledge of the plant [25].

\section{StRUCTURE AND CONFIGURATION OF CONTROLLER}

A controller is a device or logical unit used to adjust the output to a reference value. The main role of the controller is to minimize a specific error value. In this section, three feedback control schemes are proposed and described in detail which is PID, Fuzzy logic, and adaptive PID based on parameter optimization with fuzzy inference for controlling the altitude dynamics of UAV.

\section{A. PID Controller and Its Performance with Parameter Selection}

The PID control law consists of three basic feedback control actions, namely proportional, integral, and derivative. The related gains are $K_{p}, K_{i}$, and $K_{d}$. The mathematical representation of PID controller is in (5):

$$
U(t)=K_{p} e(t)+K_{i} \int_{0}^{t} e(t) d t+K_{d} \frac{d}{d t} e(t)
$$

where $\mathrm{U}(\mathrm{t})$ is the controller output and $\mathrm{e}(\mathrm{t})$ is the error.

The proportional gain diminishes the error responses to disturbances, the integral gain removes the steady-state error, and finally, the derivative gains dampen the dynamic response and enhances the system stability. The difficulty in the PID controller is to select the three gains to be suitable for the controlled plant [26]. The performance of the system can be enhanced by adapting the value of the controller gains.

\section{B. Fuzzy Logic Control}

Fuzzy control is a design of many-value logic that nearly human language. Fuzzy control is more robust than PID control since it can include a wider range of operating conditions and can perform with disturbances and noise. The fuzzy logic control comprises four main components: rule-base, inference engine, fuzzification, and defuzzification as in Fig. 2. 


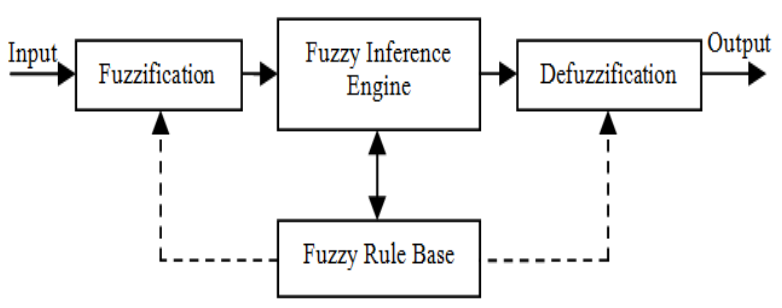

Fig. 2. Fuzzy logic control.

The rule base is the main component, based on if-then rules, and holds the knowledge of how best to control the system. Inference engine evaluates which control rules are related at the current time. Fuzzification is the process of transforming crisp input values into grades of membership functions. Defuzzification is a method for providing the output of the fuzzy controller as a crisp input to the plant.

In this design, two input variables $(e(t), \dot{e}(t))$ and the output $u(t)$ are expressed over the interval from -10 to 10 . There are five linguistic terms: negative big (NB), negative small (NS), zero (Z), positive small (PS), and positive big (PB). Membership functions are Triangular form and the fuzzy rules are as in Table I.

TABLE I: FUZZY RULES FOR FUZZY CONTROLLER

\begin{tabular}{cccccc}
\multicolumn{6}{c}{ TABLE I: FUZZY RULES FOR FUZZY CONTROLLER } \\
\hline NB & NB & NS & $\mathbf{Z}$ & PS & PB \\
NS & NB & NB & NB & NS & Z \\
$\mathbf{Z}$ & NB & NB & NS & Z & PS \\
PS & NB & NS & Z & PS & PB \\
PB & NS & Z & PS & PB & PB \\
\hline \hline
\end{tabular}

\section{Adaptive PID Controller Based on Parameter Optimization with Fuzzy Inference}

Adaptive PID controller based on parameter optimization with fuzzy inference means that the three gains $K_{p}, K_{i}$, and $\mathrm{K}_{\mathrm{d}}$ of PID controller are adjusted online by using fuzzy logic control [27]-[29]. Online tuning gains of PID controller lead to enhance the adaptive performance of PID controller. The structure of the proposed adaptive PID controller is as in Fig. 3.

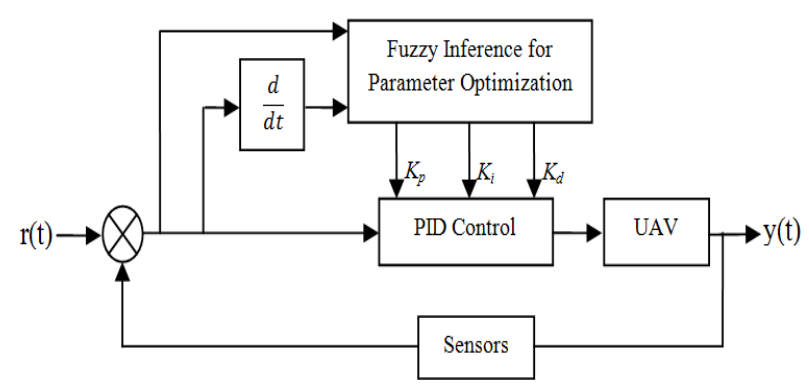

Fig. 3. The architecture of adaptive fuzzy PID controller.

In this paper, the improved PID controller is designed based on the traditional PID algorithm. The initial setting values of PID gains are set and the added values are obtained online using fuzzy control. The final gains of the adaptive PID controller can be calculated from (6) to (8).

$$
\begin{gathered}
k_{p}=k_{p o}+\Delta k_{p} \\
k_{i}=k_{i o}+\Delta k_{i} \\
k_{d}=k_{d o}+\Delta k_{d}
\end{gathered}
$$

where $k_{p o}, k_{i o}$, and $k_{d o}$ are initial values of the proportional, integral, and derivative gains; respectively. $\Delta k_{p}, \Delta k_{i}$, and $\Delta k_{d}$ are the proportional, integral, and derivative gains calculated using online fuzzy control; respectively. $k_{p}, k_{i}$, and $k_{d}$ are final values of the proportional, integral, and derivative gains; respectively.

Two inputs are considered for fuzzy control, e(t) and e $(\mathrm{t})$. In addition, three output are obtained from the fuzzy inference include $\Delta \mathrm{K}_{\mathrm{p}}, \Delta \mathrm{K}_{\mathrm{i}}$, and $\Delta \mathrm{K}_{\mathrm{d}}$. For the inputs, 7 levels are assumed which are negative big (NB), negative medium (NM), negative small (NS), zero (Z), positive small (PS), positive medium (PM), positive big (PB). The ranges for these inputs are from -3 to 3 as in Fig. 4.

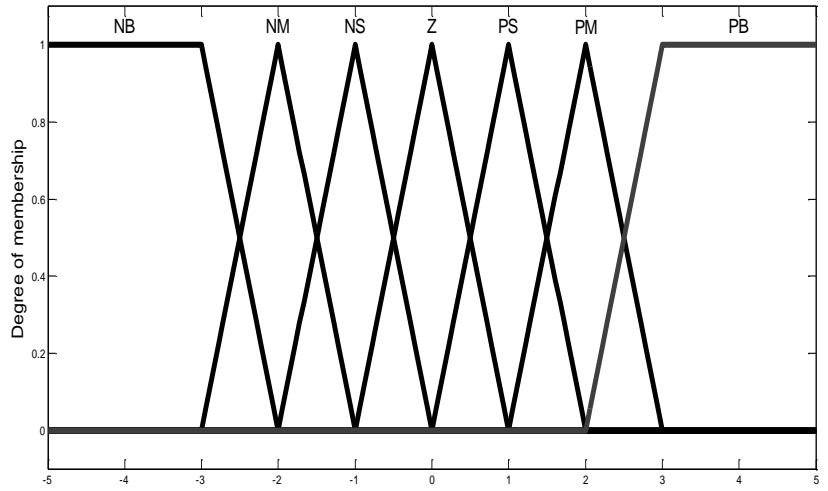

Fig. 4. Input membership function for $K_{p}, K_{i}$, and $K_{d}$.

For the output, 3 levels are assumed which are negative $(\mathrm{N})$, zero $(\mathrm{Z})$, and positive $(\mathrm{P})$. The ranges of the outputs are from -3 to 3 for $\Delta K_{p}$ as in Fig. 5 and from -1 to 1 for $\Delta K_{i}$ and $\Delta \mathrm{K}_{\mathrm{d}}$ as in Fig. 6.

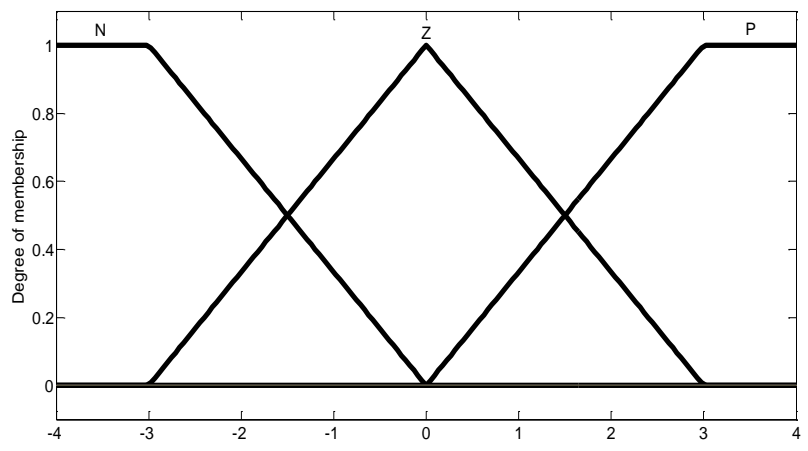

Fig. 5. Output membership function for $\Delta K_{p}$.

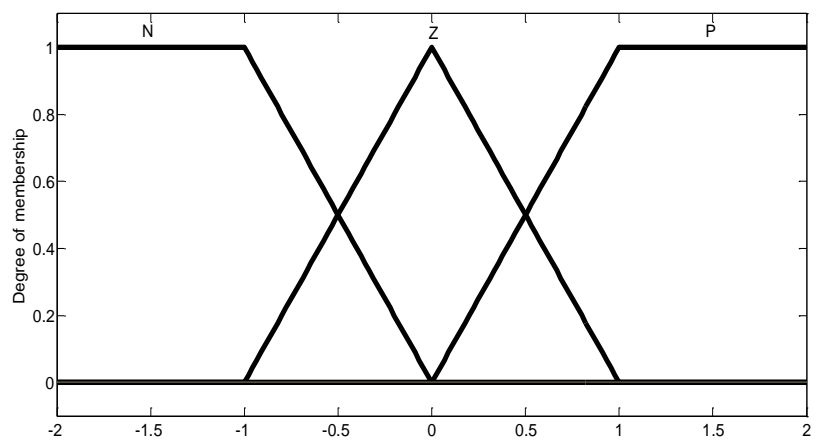

Fig. 6. Output membership function for $\Delta K_{i}$ and $\Delta K_{d}$. 
The fuzzy rules of three outputs are presented in Tables II to Tables IV. The fuzzy rules are designed based on human experience and are a criterion for making decisions about the system.

TABLE II: $\Delta K_{p}$ FUZZY RULES

\begin{tabular}{|c|c|c|c|c|c|c|c|}
\hline 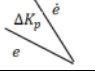 & NB & NM & NS & $\mathbf{Z}$ & PS & PM & PB \\
\hline NB & $P$ & $\mathrm{P}$ & $\mathrm{P}$ & $\mathrm{P}$ & $\mathrm{P}$ & $\mathrm{P}$ & $\mathrm{P}$ \\
\hline NM & $\mathrm{Z}$ & $\mathrm{P}$ & $\mathrm{P}$ & $\mathrm{P}$ & $\mathrm{P}$ & $\mathrm{P}$ & $\mathrm{Z}$ \\
\hline NS & $\mathrm{N}$ & $\mathrm{Z}$ & $\mathrm{Z}$ & $P$ & $\mathrm{Z}$ & $\mathrm{Z}$ & $\mathrm{N}$ \\
\hline $\mathbf{Z}$ & $\mathrm{N}$ & $\mathrm{N}$ & $\mathrm{N}$ & $\mathrm{Z}$ & $\mathrm{N}$ & $\mathrm{N}$ & $\mathrm{N}$ \\
\hline PS & $\mathrm{N}$ & $\mathrm{Z}$ & $\mathrm{Z}$ & $\mathrm{P}$ & $\mathrm{Z}$ & $\mathrm{Z}$ & $\mathrm{P}$ \\
\hline PM & $\mathrm{Z}$ & $\mathrm{P}$ & $\mathrm{P}$ & $\mathrm{P}$ & $\mathrm{P}$ & $\mathrm{P}$ & $\mathrm{Z}$ \\
\hline PB & $\mathrm{P}$ & $\mathrm{P}$ & $\mathrm{P}$ & $\mathrm{P}$ & $\mathrm{P}$ & $\mathrm{P}$ & $\mathrm{P}$ \\
\hline \multicolumn{8}{|c|}{ TABLE III: $\Delta K_{i}$ FUZZY RULES } \\
\hline$e_{e}^{\Delta K_{i}} e^{\dot{e}}$ & NB & NM & NS & $\mathbf{Z}$ & PS & PM & PB \\
\hline NB & $\mathrm{P}$ & $\mathrm{P}$ & $\mathrm{P}$ & $\mathrm{P}$ & $\mathrm{P}$ & $\mathrm{P}$ & $\mathrm{P}$ \\
\hline NM & $\mathrm{Z}$ & $\mathrm{Z}$ & $\mathrm{P}$ & $\mathrm{P}$ & $\mathrm{P}$ & $\mathrm{Z}$ & $\mathrm{Z}$ \\
\hline NS & $\mathrm{N}$ & Z & $\mathrm{Z}$ & $\mathrm{P}$ & $\mathrm{Z}$ & $\mathrm{Z}$ & $\mathrm{N}$ \\
\hline $\mathbf{Z}$ & $\mathrm{N}$ & $\mathrm{N}$ & $\mathrm{N}$ & $\mathrm{Z}$ & $\mathrm{N}$ & $\mathrm{N}$ & $\mathrm{N}$ \\
\hline PS & $\mathrm{N}$ & Z & Z & $\mathrm{P}$ & $\mathrm{Z}$ & Z & $\mathrm{P}$ \\
\hline PM & $\mathrm{Z}$ & $\mathrm{Z}$ & $\mathrm{P}$ & $\mathrm{P}$ & $\mathrm{P}$ & Z & $\mathrm{Z}$ \\
\hline PB & $\mathrm{P}$ & $\mathrm{P}$ & $\mathrm{P}$ & $\mathrm{P}$ & $\mathrm{P}$ & $P$ & $\mathrm{P}$ \\
\hline
\end{tabular}

TABLE IV: $\Delta K_{d}$ FUZZY RULES

\begin{tabular}{cccccccc}
\hline \hline$\underbrace{\Delta K_{d}^{\prime}}_{e}$ & $\mathbf{N B}$ & $\mathbf{N M}$ & $\mathbf{N S}$ & $\mathbf{Z}$ & $\mathbf{P S}$ & $\mathbf{P M}$ & $\mathbf{P B}$ \\
\hline $\mathbf{N B}$ & $\mathrm{N}$ & $\mathrm{N}$ & $\mathrm{N}$ & $\mathrm{N}$ & $\mathrm{N}$ & $\mathrm{N}$ & $\mathrm{N}$ \\
$\mathbf{N M}$ & $\mathrm{P}$ & $\mathrm{Z}$ & $\mathrm{N}$ & $\mathrm{N}$ & $\mathrm{N}$ & $\mathrm{Z}$ & $\mathrm{P}$ \\
$\mathbf{Z}$ & $\mathrm{P}$ & $\mathrm{P}$ & $\mathrm{Z}$ & $\mathrm{N}$ & $\mathrm{Z}$ & $\mathrm{P}$ & $\mathrm{P}$ \\
$\mathbf{P S}$ & $\mathrm{N}$ & $\mathrm{P}$ & $\mathrm{P}$ & $\mathrm{Z}$ & $\mathrm{P}$ & $\mathrm{P}$ & $\mathrm{P}$ \\
$\mathbf{P M}$ & $\mathrm{P}$ & $\mathrm{P}$ & $\mathrm{Z}$ & $\mathrm{N}$ & $\mathrm{Z}$ & $\mathrm{Z}$ & $\mathrm{N}$ \\
$\mathbf{P B}$ & $\mathrm{P}$ & $\mathrm{Z}$ & $\mathrm{N}$ & $\mathrm{N}$ & $\mathrm{N}$ & $\mathrm{Z}$ & $\mathrm{P}$ \\
\hline \hline
\end{tabular}

\section{Simulation EXPERIMENT RESUltS AND COMPARATIVE} ANALYSIS

An adaptive PID control is designed based on parameter optimization with fuzzy inference system for controlling the altitude dynamics of UAV. To show the effectiveness of the proposed adaptive PID control, it is compared with both genetically-tuned PID control and fuzzy logic control. The simulation results for the three different controllers based on the full nonlinear model are analyzed from performance and robustness points of view. This nonlinear model takes into account the complexity of the aerodynamic forces and moments. Moreover, the controllers were designed in
Matlab/Simulink with a sampling time of $0.02 \mathrm{~s}$, using the Runge-Kutta solver. Finally, external disturbances represented by the wind in the $\mathrm{X}-\mathrm{Y}$ plane are taken into consideration to verify the robustness of each controller.

Comparison between an optimally-tuned PID by GA, fuzzy logic, and adaptive PID controller was done through the simulation. The optimal PID tuned using GA produced the following parameters: $k_{p}=0.5516, k_{i}=0.3162$, and $k_{d}=0.0188$. The fuzzy control produced the following parameters: $k_{e}=0.3283, k_{\dot{e}}=0.038$, and $k_{u}=0.9949$.

The response of the autopilot of the longitudinal motion of the UAV is plotted in Fig. 7. The figure shows approximately similar response for the three types of controllers when the UAV is not subjected to wind disturbance or any uncertainty.

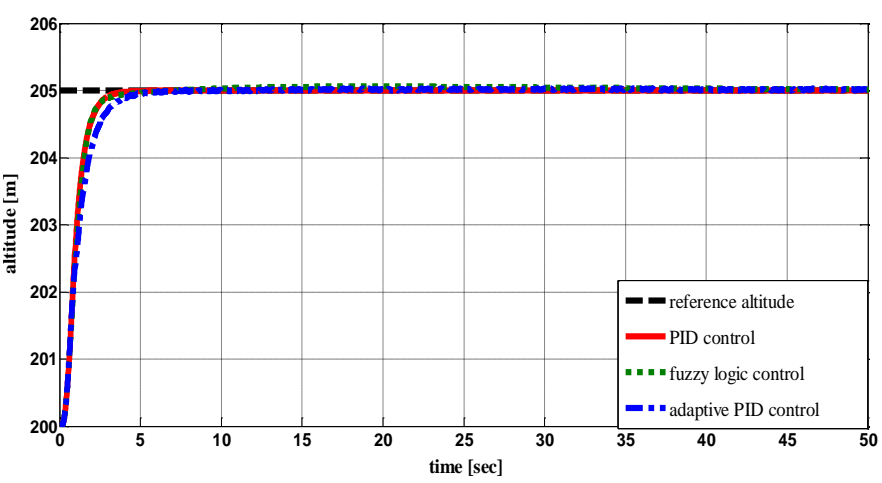

Fig. 7. Autopilot response for longitudinal motion.

Fig. 8 shows the three autopilot responses for tracking a reference altitude. Fig. 8 shows approximately identical responses for altitude tracking for the three autopilots. In each step up or down the speed is affected instantaneously because of the coupling effect.

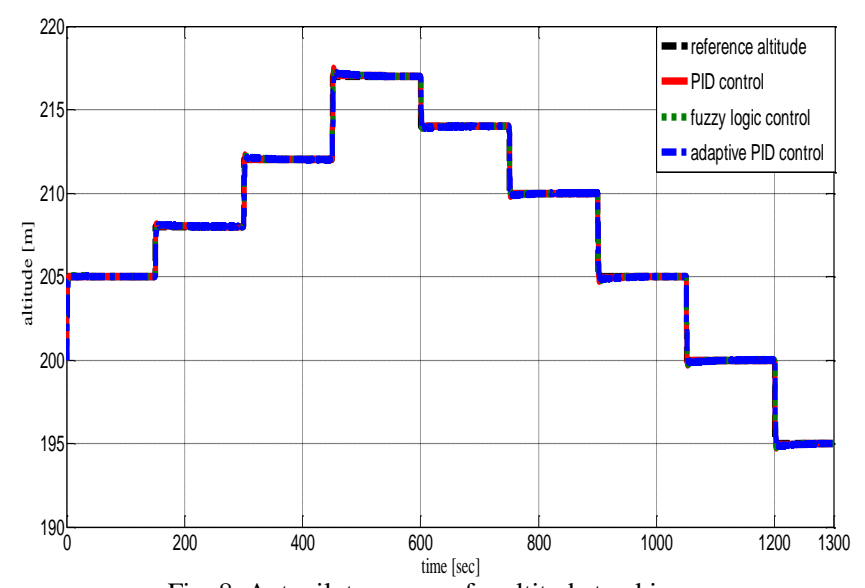

Fig. 8. Autopilot response for altitude tracking.

\section{A. Advantages in Disturbance Rejection}

The effect of crosswind disturbance in the X-Y plane is studied in this subsection. The UAV is subjected to crosswind disturbance in the $\mathrm{X}-\mathrm{Y}$ plane. The desired altitude has to be tracked by the Aerosonde UAV autopilot.

From Fig. 9 it should be noted from a robust performance point of view, the best autopilot controller is the adaptive PID controller since it produces less overshoot and less settling time.

\section{B. Well Performance to Overcome Uncertainties}

The robustness of the designed flight controller in the 
presence of UAV parametric uncertainties is validated and tested in this subsection. From Fig. 10, the autopilot utilized adaptive PID controller provides best robust performance and robust stability point of view.

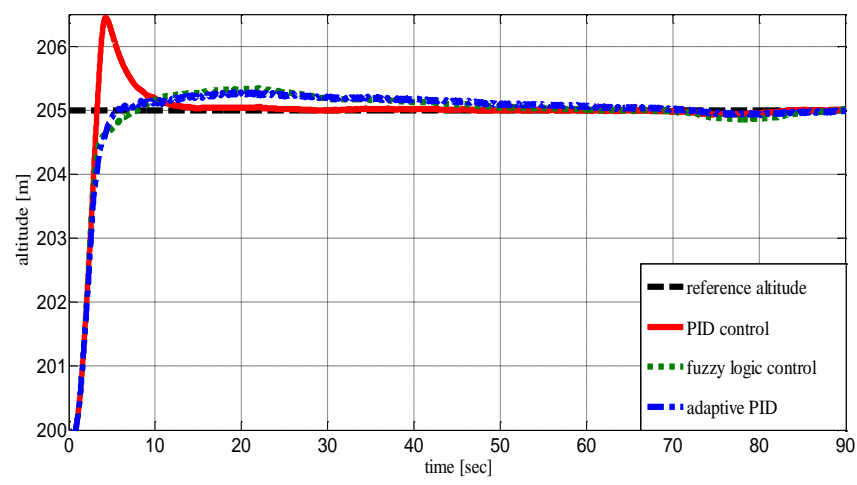

Fig. 9. Autopilot response for altitude tracking in the presence of wind.

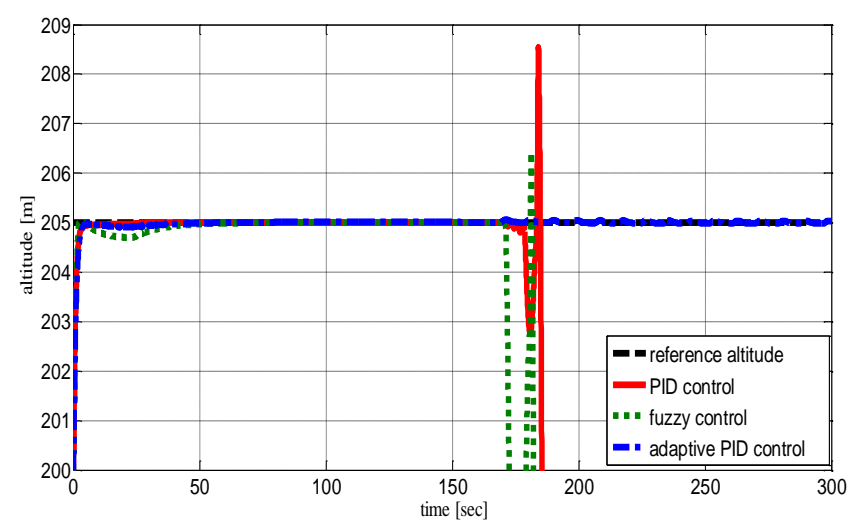

Fig. 10. Autopilot response for altitude tracking in the presence of parametric uncertainties.

\section{CONCLUSION AND REMARKS}

An adaptive PID controller based on parameter optimization with fuzzy inference system is designed for Aerosonde autopilot as a fixed wing UAV. The online fuzzy inference is used as the fine tuning mechanism for PID controller. This controller is compared with genetically-tuned PID controller. It is also compared with fuzzy logic controller. The comparison based on simulation results obtained from Aerosonde UAV model. The comparison is done from three points of view; tracking performance, robustness to wind disturbances, and parametric uncertainty of the UAV.

The simulation results show approximately similar autopilot performances when the UAV is not subjected to any external disturbances. The autopilot controlled by adaptive PID achieves an excellent performance when dealing with external wind disturbances and UAV parametric uncertainty.

\section{ACKNOWLEDGMENT}

This work was partly supported by National Natural Science Foundation of China under Grant 61273350 and Grant U1435220

\section{REFERENCES}

[1] A. Brezoescu, T. Espinoza, P. Castillo, and R. Lozano, "Adaptive trajectory following for a fixed-wing UAV in presence of crosswind," Journal of Intelligent and Robotic Systems, vol. 69, January 2013.

[2] N. Wahid and N. Hassan, "Self-tuning Fuzzy PID Controller Design for Aircraft Pitch Control," in Proc. IEEE $3^{\text {rd International Conference }}$ on Intelligent Systems Modeling and Simulation, 2012, pp. 19-24.
[3] L. Qiu, J. Q. Yi, G. L. Fan, W. S. Yu, and R. Y. Yuan, "Design of robust backstepping controller for unmanned aerial vehicle using analytical redundancy and extended state observer," in Proc. IEEE International Robotics and Biomimetics Conference (ROBIO), pp. 1935-1940, Guilin, 2009.

[4] S. Y. Yang, K. Q. Li, and J. Shi, "design and simulation of the longitudinal autopilot of uav based on self-adaptive fuzzy pid control," in Proc. IEEE International Conference on Computational Intelligence and Security, vol. 1, Beijing, 2009.

[5] W. T. M. S. Tennakoon and S. R. Munasinghe, "Design and simulation of a UAV controller system with high maneuverability," in Proc. 4th IEEE International Conference on Information and Automation for Sustainability ICIAFS, Colombo, 2008.

[6] L. W. Qiu, J. Q. Yi, G. L. Fan, W. S. Yu, and R. Y. Yuan, "Design of robust backstepping controller for unmanned aerial vehicle using analytical redundancy and extended state observer," in Proc. 3rd IEEE International Symposium on Systems and Control in Aeronautics and Astronautics (ISSCAA), Harbin, 2010.

[7] S. Park, J. Deystt, and J. P. How, "Performance and Lyapunov stability of a nonlinear path-following guidance method," J. Guidance, Control, Dyn., vol. 30, no. 6, pp. 1718-1728, 2007.

[8] J. H. Zhu, "A survey of advanced flight control theory and application," in Proc. IEEE IMACS Multi Conference on Computational Engineering in Systems Applications (CESA), China, 2006.

[9] L. W. Qiu, G. L. Fan, J. Q. Yi, and W. S. Yu," Design of neural network and backstepping based adaptive flight controller for multi-effector Uav," in Proc. IEEE International Conference on Robotics and Biomimetics, 2009.

[10] L. W. Qiu, G. L. Fan, J. Q. Yi, and W. S. Yu, "Robust hybrid Controller design based on feedback linearization and $\mu$ synthesis for UAV," in Proc. $2^{\text {nd }}$ IEEE International Conference on Intelligent Computation Technology and Automation, vol. 1, Hunan 2009.

[11] Puneet Wahi, Ravi Rania and Fahmida N Chowdhury, "A Survey of Recent Work in Adaptive Flight Control", Proceedings of the $33^{\text {rd }}$ IEEE Southeastern Symposium on System Theory, Athens, 2001.

[12] P. B. Sujit, S. Saripalli, and J. B. Sousa, "A survey and analysis of algorithms for fixed-wing unmanned aerial vehicles," IEEE Control Systems Magazine, vol. 34, pp. 42 - 59, 2014.

[13] B. B. Alagoz, A. Ates, and C. Yeroglu, "Auto-tuning of PID controller according to fractional-order reference model approximation for DC rotor control," Mechatronics, vol. 23, no. 7, pp. 789-79, 2013.

[14] G. P. Liua and S. Daleyb, "Optimal-tuning PID control for industrial systems," Control Engineering Practice, vol. 9, no. 11, pp. 1185-1194 2001.

[15] X. Zhang, D. Y. Zhou, J. Zhang, Q. Pan, and K. Zhang, "Based on backstepping control with time-delay estimation and nonlinear damping adaptive PID control for unmanned aerial vehicle," in Proc. the 2015 IEEE International Conference on Information and Automation, Lijiang, China, August 2015.

[16] M. S. Saad, M. Jamaluddin, and I. Z. M. Darus, "Implementation of PID controller tuning using differential evolution and genetic algorithms," International Journal of Innovative Computing, Information, and Control, 2012, vol. 8, no. 11, pp. 7761-7779.

[17] M. Tokuda and T. Zamamoto, " Self-tuning PID controller based on control performance evaluations," International Journal of Innovative Computing, Information, and Control 2010; vol. 6, no. 8, pp. 3751-3762.

[18] A. Panbude and M. Sharma, "Implementation of neural network for PID controller," International Journal of Computer Applications Proceedings on National Conference on Emerging Trends in Advanced Communication Technologies, 2015.

[19] K. V. Lakshmi and P. Srinivas, "Optimal tuning of PID controller using particle swarm optimization," in Proc. International Conference on Electrical, Electronics, Signals, Communication and Optimization, pp. $1-5,2015$.

[20] B. L. Stevens and F. L. Lewis, Aircraft Control and Simulation, John Wiley \& Sons, Inc. second edition, 2003.

[21] R. Socas, S. Dormido, and R. Dormido, "Event-based control strategy for the guidance of the Aerosonde UAV," in Proc. IEEE European Conference on Mobile Robots (ECMR), pp. 1-6, 2015.

[22] R.W. Beard and T.W. McLain, Small Unmanned Aircraft, Theory and Practice, Princeton University Press, 2012.

[23] A. R. Girard, S. Dharba, M. Pachter, and P. R. Chandler, "Stochastic dynamic programming for uncertainty handling in UAV operations," in Proc. IEEE American Control Conference, pp. 1079-1084, 2007.

[24] M. Sadraey and $\uparrow$ R. Colgren, "Two DOF robust nonlinear autopilot design for a small UAV using a combination of dynamic inversion and H_loop shaping," 2005. 
[25] A. A. Ghaffar and T. Richardson, "Model reference adaptive control and LQR control for quadrotor with parametric uncertainties," International Journal of Mechanical, Aerospace, Industrial, Mechatronic and Manufacturing Engineering, vol. 9, no. 2, 2015.

[26] M. A. Shamseldin and A. A. EL-Samahy, "Speed control of BLDC motor by using PID control and self-tuning fuzzy PID controller," in Proc. $15^{\text {th }}$ IEEE International Workshop on Research and Education in Mechatronics (REM), El Gouna, 2014.

[27] K. Sinthipsomboon, W. Pongaen, and P. Pratumsuwan, "A hybrid of fuzzy and fuzzy self-tuning PID controller for servo electro-hydraulic system," in Proc. $6^{\text {th }}$ IEEE Conference on Industrial Electronics and Applications (ICIEA), Beijing, 2011.

[28] B. Feng, G. F. Gong, and H. Y. Yang, "Self-tuning parameter fuzzy PID temperature control in a large hydraulic system," in Proc. IEEE/ASME International Conference on Advanced Intelligent Mechatronics, 2009, pp.1418-1422.

[29] X. Gong, L. F. Wang, and Z. J. Meng, "Fuzzy self-tuning PID controller for an unmanned helicopter," in Proc. the $34^{\text {th }}$ IEEE Chinese Control Conference, China, 2015.

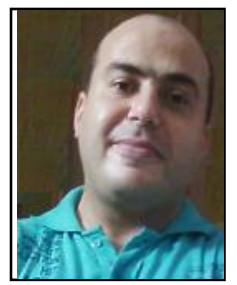

Amr Sarhan received the B.S. degree in electrical engineering from Military Technical College, Cairo, Egypt, in 2002; a senior researcher until 2006. In 2011 he has received the M.S. degree from Military Technical College, Cairo, Egypt; a lecture assistant in aircraft special equipments department at Military Technical College, Cairo, Egypt. He is interested in unmanned aerial vehicles flight control systems. He currently a Ph.D. candidate in UAV flight control system from School of Automation Science and Electrical Engineering in Beihang University (Beijing University of Aeronautics and Astronautics), Beijing, China.

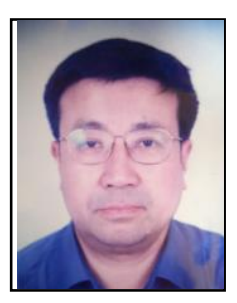

Shiyin Qin received his bachelor's and a master's degrees in engineering science in automatic controls and industrial systems engineering from Lanzhou Jiaotong University in 1978 and 1984, respectively, and $\mathrm{He}$ received his $\mathrm{PhD}$ degree in industrial control engineering and intelligent automation from Zhejiang University in 1990. He is now a professor at the School of Automation Science and Electrical Engineering in Beihang University (Beijing University of Aeronautics and Astronautics). His current major research topics include image processing and pattern recognition, intelligent control systems of UAVs, intelligent optimizing controls of large scale multi-robot hybrid systems, complex systems and complexity science, etc. 